\title{
El cine de Costa-Gavras en el siglo XXI: representaciones de la idea de Europa
}

\section{Costa-Gavras'cinema in the XXI century: Representations of the idea of Europe}

\author{
Ricardo Jimeno Aranda \\ Universidad Complutense de Madrid, España \\ rijimeno@ucm.es \\ José Antonio Jiménez de las Heras \\ Universidad Complutense de Madrid, España \\ jajlasheras@ccinf.ucm.es
}

\section{Resumen:}

El artículo se centra en la última etapa del cine del director franco-griego Costa-Gavras, referente principal del cine político contemporáneo, en la que aborda las fracturas de una Europa posmoderna desde múltiples ángulos. Gavras traza un recorrido que va desde los estragos del desempleo y de la competencia empresarial en Arcadia (Le couperet, 2005), la realidad de la inmigración ilegal en Edén al Oeste (Éden à l'Ouest, 2009), el funcionamiento especulativo de la economía en El capital (Le capital, 2012), y el engranaje institucional de la Unión Europea en Comportarse como adultos (Adults in the Room, 2019). El texto se centra en analizar como este grupo de filmes ofrecen, a partir de su construcción narrativa y discursiva, una visión de la deriva europea contemporánea en un sentido dual, entre realidad y utopía, a partir de un tono de realismo mágico, que se convierte en la metáfora de la de la crisis de valores de la Unión Europea.

\begin{abstract}
:
This article focuses on the last phase in the filmography of French-Greek director Costa-Gavras, one of the main references in contemporary political cinema, in which he reveals the fractures of a postmodern Europe from multiple angles. Gavras's films trace a path that goes from the ravages of unemployment in The Ax (Le couperet, 2005) to the stark reality of illegal immigration in Eden is West (Éden à l'Ouest, 2009), the speculative mechanisms of the economy in Capital (Le capital, 2012), and into the institutional heart of the European Union in Adults in the Room (2019). The investigation shows how the narrative and discursive constructions of these film offer a vision of contemporary European drift in a dual sense between reality and utopia: they do so by adopting a tone of magical realism that becomes a metaphor for the crisis of values under way in the European Union.
\end{abstract}

Palabras clave: cine político; Costa-Gavras; Europa; Unión Europea; inmigración; globalización.

Keywords: Political Cinema; Costa-Gavras; Europe; European Union; Immigration; Globalization. 


\section{Introducción}

\subsection{Costa-Gavras, trayectoria en el siglo XXI}

Costa-Gavras (Arcadia, 1933) es uno de los cineastas fundamentales del cine político y social contemporáneo, y su propia figura como director está unida al poliédrico concepto de cine político desde su época de esplendor en los años sesenta y setenta del siglo XX. Su obra ha sido reflejo del devenir del contexto político internacional, mostrando a través de películas que han trascendido su condición cinematográfica para erigirse en manifiestos políticos, algunos de los principales acontecimientos del siglo XX, como el Holocausto judío - Amén (Amen, 2002) - , los horrores del estalinismo - La confesión (L'aveu, 1970)—, o las consecuencias de los regímenes dictatoriales en Europa $-Z$ (id., 1969) - o en América Latina - Estado de sitio (État de siège, 1972) y Desaparecido (Missing, 1982)-.

Partiendo de esta trayectoria y de una forma fílmica muy determinada, consciente de provocar la reflexión, pero sin despreciar la idea del cine como espectáculo - de hecho, potenciándola, para lograr el acceso a un público amplio-, Costa-Gavras ha continuado en activo hasta la actualidad, con la preocupación constante de reflexionar sobre las transformaciones sociales y políticas de la sociedad contemporánea. Por esa circunstancia, su filmografía reciente se convierte en un espejo continuo de la evolución de Europa, que va deteniéndose puntualmente en alguno de los grandes problemas, retos y crisis de las primeras dos décadas del siglo XXI.

\subsection{Las obras objeto de estudio: una tetralogía europea}

Arcadia (Le couperet, 2005) está basada en una novela negra de Donald Westlake, adaptada por Gavras con su guionista habitual de esta etapa, el dramaturgo Jean-Claude Grumberg, que colabora con él en todos los filmes posteriores, salvo en Comportarse como adultos (Adults in the Room, 2019), escrito en solitario por Gavras. La película aborda el problema del desempleo y de la competencia feroz para conseguir trabajo, a partir de la historia de Bruno (José García), ejecutivo de una empresa papelera que se queda en paro y ante la imposibilidad de ser contratado de nuevo, decide eliminar físicamente a sus competidores. El filme toma la forma de una sátira negra, 
con ecos de thriller. Esta adscripción genérica, a la que se suma el tono de humor negro, permite al cineasta dar una vuelta de tuerca metafórica sobre el problema social que trata en la película, llevándolo al paroxismo. Al mismo tiempo, los mecanismos de construcción del suspense, basados en la dosificación de información al público, permiten que el segundo acto del filme siga el molde narrativo de los títulos con un falso culpable, aunque en este caso se trate de un culpable cierto, si bien con las simpatías del público ganadas.

Por su parte, Edén al Oeste (Éden à l'Ouest, 2009) es una fábula sobre la inmigración, que narra el viaje de un refugiado, Elías (Riccardo Scamarcio). El filme tiene tres partes diferentes, una primera que narra la llegada del protagonista a la costa europea y su estancia clandestina en una urbanización de vacaciones; su viaje a través de Europa, donde sufre diversas aventuras, y su llegada a París, epílogo notablemente surrealista. Gavras aporta de nuevo una cobertura con tintes de comedia, o de cuento amable, como si pretendiese suavizar de algún modo lo terrible de la historia que aborda. De hecho, el filme contiene alguna construcción típica del slapstick, lo que sumado a la condición prácticamente muda del personaje - no habla para no desvelar su condición de extranjero- aproximan al filme a la lógica de las comedias sociales de Charles Chaplin, con un héroe en los márgenes, inocente y luchador. Asimismo, la película, por su estructura narrativa, contiene expresos ecos de La odisea de Homero y de la literatura de Dickens, además de ser el único de los filmes en el que pueden hallarse algunas claves autobiográficas del autor. Costa-Gavras, nacido en Grecia, llegó a París a los veinte años, en 1955, huyendo de una situación sin futuro en Grecia, y teniendo sus esperanzas depositadas en un París visto como una especie de tierra prometida: "No es una autobiografía. Aunque es cierto que Elías está inspirado en mi vida, en mis experiencias". (Ravanello, 2009).

El capital (Le capital, 2012) es una adaptación libre de la obra homónima de Stéphane Osmont. El filme retrata el ascenso de un cínico ejecutivo sin escrúpulos, Marc Tourneuil ( $\mathrm{Gad}$ Elmaleh), en un entorno financiero globalizado, mostrando el funcionamiento del sistema empresarial y 
económico global. El personaje se convierte fortuitamente en el presidente de un banco francés tras la muerte de su antecesor, y comienza a redoblar la apuesta por evadir impuestos, a través de paraísos fiscales. Se inicia así una lucha de poder con diferentes modos de hacer, entre accionistas tradicionales, y especuladores cortoplacistas. El filme narra su ascenso de modo circular, al mismo ritmo que el movimiento del dinero, y construye una subtrama sentimental, que se plantea como única barrera ética a la falta de escrúpulos del personaje. Gavras se sirve en este caso de otros mitos y referentes literarios, como Fausto o Dorian Gray, el personaje pierde todo a nivel emocional, cambiándolo por el éxito económico.

Finalmente, Comportarse como adultos (Adults in the Room, 2019) -su último filme hasta la fecha- adapta las memorias del exministro de economía Yanis Varoufakis, al que toma como protagonista (interpretado por Christos Loulis) y narra sus conflictos con las instituciones europeas durante la crisis griega. El filme ofrece una descripción despiadada de las relaciones políticas e institucionales dentro de la Unión Europa, revelando su fracaso y su deriva ideológica, a partir de nuevo de una estructura de viaje metafórico en tres actos: la victoria de Syriza en las elecciones griegas, el desarrollo del combate de Varoufakis contra la troika, la Comisión y el Consejo europeos, donde el ministro alemán, ejerce como antagonista, y su derrota final. En paralelo, de modo dramático, se expone la progresiva separación entre Varoufakis y el primer ministro Alexis Tsipras (Alexandros Bordoumis), por las diferencias políticas que van surgiendo. Es una infrecuente incursión de Gavras en un hecho concreto de la historia reciente, conservando los nombres de los responsables y protagonistas del conflicto, algo insólito en su obra.

Las cuatro películas tienen una temática transversal común centrada en determinados acontecimientos actuales, concretos o genéricos, que marcan el surgimiento de grietas profundas en una determinada visión del sueño de la construcción europea, interrelacionando retos, problemas y particularmente las causas de dicho declive. 


\subsection{La relación entre la realidad europea y el cine de Gavras}

La relación entre el cine -lo que podría extenderse lógicamente al audiovisual, en general- y la política (como elemento concreto de un concepto más amplio, que podría ser la realidad misma) tiene un carácter bidireccional, es decir, una influencia recíproca, como aprecia el investigador norteamericano James Combs cuando habla de una "relación dinámica" y explica que "las películas han llegado a contribuir en el desarrollo de los comportamientos dentro del discurso social y político" (Combs, 1993, p. 4).

Esta relación bidireccional puede observarse de forma modélica en la obra de Costa-Gavras. Sus películas no solamente han reflejado la realidad de su tiempo, como explicábamos en el epígrafe introductorio, sino que en múltiples ocasiones - particularmente con sus películas de mayor éxito-, han logrado un impacto de reseñable en la propia realidad política, modificando la opinión pública sobre un acontecimiento, como ocurrió, por ejemplo, con Desaparecido al destapar de modo expreso la participación norteamericana en el golpe chileno.

En la parte de su filmografía objeto de este artículo, esta confrontación entre realidad y ficción parte del convulso contexto europeo de las dos primeras décadas del siglo XXI, presentado de un modo crítico, e incluso de la propia experiencia del cineasta - referente europeo de la industria, también como presidente de la Cinémathèque Française- en su confrontación personal con la Comisión Europea, particularmente con su presidente José Manuel Durao Barroso, en defensa de la excepción cultural europea frente a los intentos de liberalizar el sector (Gavras, 2019, pp. 480-483).

La Europa del nuevo siglo se ha caracterizado por una serie de retos internos y externos, relacionados colateralmente con las disensiones en el seno de la Unión Europea. En este sentido, la Gran Recesión, iniciada en 2008, supuso una de las pruebas de fuego, poniendo de manifiesto la debilidad, tanto de los sistemas políticos de los Estados-nación como de las instituciones europeas, sometidas a los principios de actuación del mercado global. Las consecuencias de esta crisis institucional y económica provocaron una crisis social que tiene como efecto principal un incremento exponencial del paro, 
de la precariedad y de la pobreza, especialmente agravada por periodos previos de expansión basados en la especulación inmobiliaria, como demuestra el economista Michael Talin (2014, p. 24). Es decir, como plantean las obras de Gavras, el espejismo de la riqueza material que ambienta los escenarios de la acción - recordemos que Arcadia y Edén al Oeste son filmes previos a la explosión de la crisis-, tenía de facto un reverso mucho más siniestro en sus consecuencias.

Pero paralelamente, la inestabilidad del contexto internacional, agravado por la amenaza terrorista y los diversos conflictos bélicos derivados del 11 de septiembre en Estados Unidos generan dos retos mayores: un incremento de la presión inmigratoria, que se ha visto multiplicado a partir de la Guerra de Siria, y un miedo interior -incrementado por grandes ataques terroristas ocurridos en el seno de Europa- que ha favorecido, junto a la inseguridad económica generada por la crisis, la proliferación de opciones políticas antisistema de corte populista, que además han planteado respuestas nacionalistas contrarias a la integración europea.

Curiosamente, estos elementos se adivinan colateralmente en las películas de Gavras, que se anticipa al punto álgido de estas crisis. Arcadia retrata el problema del desempleo y de la precarización social en 2005, antes del estallido de la crisis; mientras que Edén al Oeste aborda los problemas asociados a la inmigración en 2009, mucho antes del éxodo de refugiados de 2015 y de los dramas recurrentes con barcos que rescatan inmigrantes en el Mediterráneo - así comienza el filme del director-y que son retenidos en los puertos o en Alta Mar por la negativa de algunos países a admitirles.

A nivel institucional, como retrata particularmente el último filme del director, Comportarse como adultos, la crisis económica genera también una fragmentación mayor en el seno de la Unión, que se establece entre los endeudados países del sur, presionados por las instituciones económicas europeas para recibir los créditos o rescates en base a condicionantes que priorizan la ortodoxia económica.

Esta transformación tiene un doble alcance -que el director observa en las cuatro películas, en las que el modelo económico rige los destinos de 
personajes individuales, anónimos, comunidades o líderes políticos-, y que se refieren de modo general a la puesta en cuestión de la idea de Europa, como referente del progreso, de la igualdad y de la libertad.

Europa ha sido un centro fundamental para la transformación de la humanidad desde la antigüedad (...) Europa significa la defensa de un proyecto: la democracia contra las autarquías y contra las democracias populares. Este es el papel principal de Europa: servir de ejemplo en un mundo que se está desmoronando. (Costa-Gavras a Luis Martínez, 2020).

Por un lado, la sustitución de la decisión política por la tecnocracia económica, que lleva aparejada un cambio de paradigma ideológico -observable desde las décadas anteriores-, en donde se produce una paradoja política, con la desregulación política intensa, que se combina con una intensa presión normativa desde las instituciones económicas, con exigencias para el sector público y la toma de decisiones políticas. Este es el contexto en el que se mueve el cine de Costa-Gavras en este periodo, en una tensión entre la realidad, con derivas de repliegue y retracción, y el sueño o ideal de una Europa posible.

Partiendo de estos presupuestos, y tomando como base la relación entre la narración fílmica y el discurso ideológico-político - cuya base de partida será explicada en el epígrafe metodológico-, el objetivo del artículo se centra en estudiar las ideas de Europa que el cineasta plantea a lo largo de estas películas de modo transversal. La plasmación de conceptos diversos y complementarios de Europa, a veces incluso contradictorios, como la globalización enfrentada al pluralismo y a la multiculturalidad; el optimismo idealista - el mito y sueño de Europa- opuesto a una realidad en crisis; o la visión del individuo frente al colectivo; y de las clases precarias frente a las élites, establecen la organización del desarrollo del texto. Cada una de estas ideas introduce el análisis narrativo y político de determinados aspectos generales y concretos de las películas, puestas en relación, con la finalidad de que se comprenda de modo global la dirección precisa del discurso del cineasta en torno a su visión de Europa. 


\section{Metodología. La narrativa es política}

En un sentido estricto desde la perspectiva científica del análisis, la metodología que se emplea parte de una aproximación comparativa que deriva de un estudio de caso -las películas objeto de estudio-, pero particularmente de la interrelación entre una aproximación histórica crítica, desde una aproximación politológica al sistema social e institucional europeo de las últimas dos décadas, combinado con un análisis narrativo de las cuatro películas del cineasta Costa-Gavras que son objeto del artículo, en su consideración de obras políticas.

En este punto se toma como base el concepto de política que establece Vallés cuando habla de sus tres acepciones relacionadas con la estructura, el proceso y la toma de decisiones (2003, pp.45-46). Este concepto múltiple trasladado al medio cinematográfico permite sostener que las obras que introducen en su narrativa la reflexión sobre las instituciones, los procesos o conflictos políticos, y los efectos de las políticas públicas, pude ser considerado como cine político. Pero más allá de esta consideración, cabe tener en cuenta que más allá del tema que la película aborde, es el modo en que el cineasta plantea la narración -la construcción estructural del relato, las decisiones de puesta en escena, y la doble funcionalidad de los elementos narrativos- donde puede observarse el discurso político que la obra presenta. Este análisis parte de la perspectiva que introducen Aumont y Marie cuando dicen que "tanto en el cine como en toda producción significante no existe contenido que sea independiente de la forma en la que se expresa" (Aumont \& Marie, 2002, pp. 131-132).

Partiendo de este principio, y de la propia clasificación de estos autores que interrelaciona acción, tema y contenido de la obra cinematográfica, se puede plantear como válido un análisis, con raíces en la semiótica, que relacione los valores pragmáticos de la narración -que giran en torno a la propia lógica del argumento, a su eficacia causal para seguir una trama- y sus valores poéticos -que dotan de un sentido simbólico a los pragmáticos, de un determinado subtexto más o menos expreso-. En el caso que nos ocupa, ligando estos conceptos a los anteriores, nos encontramos con que en el cine 
de Costa-Gavras, sin que puedan anularse otros subtextos, el valor poético de sus construcciones narrativas es esencialmente de orden político.

Así, por ejemplo, como elemento fundamental en la narrativa de Gavras, aparece la construcción del punto de vista del relato. Esta decisión tiene precisamente una utilidad pragmática, pues de este modo, el espectador tiende a identificarse, dentro de la historia, con un personaje, que le guía por la historia y, a veces, -cuando esto es necesario por la complejidad del contexto presentado, como en los enrevesados escenarios presentados en $E l$ capital y en Comportarse como adultos- facilita su comprensión. Pero, al mismo tiempo, esta perspectiva permite construir un sentido simbólico, por ejemplo, planteando un posicionamiento de clase ante los hechos narrados. Otro recurso narrativo del cineasta es la aplicación de una didáctica simbólica, como apunta Navarro (2012, p. 31), que puede condensarse en el intento de descifrar determinados procesos de la realidad a través de la puesta en escena. Esto se logra igualmente a través del punto de vista, pero también con recursos más puntuales. Un ejemplo muy concreto es la utilización de animaciones que, en algunos de estos filmes, se superponen en diversos momentos a la imagen real, mostrando esquemas o cifras. Esto ayuda a comprender determinados procesos económicos necesarios para seguir la trama, pero al mismo tiempo otorga un sentido simbólico, virtual y volátil, al universo financiero que se describe.

En este sentido, y guiándonos por la relación entre valores pragmáticos y poéticos del texto, a partir de las relaciones establecidas y referidas de Aumont y Marie, o por la distinción ya clásica de Bordwell cuando diferencia entre la historia como "construcción imaginaria que creamos progresiva y retroactivamente", el argumento como "organización real de la historia en la película", y el estilo como "uso sistemático de los recursos cinematográficos" en cuanto a conceptos estrictamente narrativos (Bordwell, 1996: pp. 49-50), a los que asocia unas funciones significativas o "poéticas", que actúan como una forma totalizadora. Es decir, no estableciendo una interpretación -que en este caso sería ideológica o política- desde fuera de la narración, sino teniendo en cuenta que "los significados tanto implícitos como explícitos dependen de las relaciones entre los elementos de la narración y el estilo" y 
que estos significados "son en el fondo ideológicos, es decir, proceden de sistemas de creencias culturales específicas sobre el mundo" (Bordwell y Thompson, 1995: pp.51-52). Este presupuesto es la base de nuestro análisis: la constatación de que el significado político de la obra se construye a partir de la selección concreta de recursos narrativos y de puesta en escena, que trascienden la simple apreciación interpretativa externa del tema de la película.

\section{Las ideas de Europa}

\subsection{La Europa única como metáfora de la globalización}

Una de las claves de los cuatro filmes es la voluntad consciente de ser inconcreto a la hora de situar de forma exacta, con algunas leves excepciones, la ubicación geográfica de los relatos. Es una tradición en la obra de Gavras que tiene el propósito de universalizar las narraciones, evitando el localismo. No obstante, en este caso adquieren además de esa lógica práctica, otra simbólica, pues constituyen una metáfora de la Europa única de la globalización.

Esta idea puede verse en todas las obras, pero particularmente en las dos primeras, Arcadia y Edén al Oeste. En estas películas Europa se reduce a un conjunto de urbanizaciones, ciudades y autopistas monocordes e indistinguibles, como representación de una unidad basada exclusivamente en el movimiento del capital y de las mercancías. En Arcadia, la plasmación visual -típica del polar, el género policiaco francés- es grisácea, casi distópica. Esa indeterminación espacial combina paisajes idénticos y deshumanizados que el protagonista atraviesa buscando a sus próximas víctimas, potenciales ocupantes de los puestos que el puede desempeñar. En su desempeño autónomo, en su libre iniciativa, su acción criminal, torpe al comienzo, va adquiriendo a lo largo del filme una profesionalidad notable, lo que redunda en una vuelta de tuerca cínica, en una ordenada "lógica de la locura" (Morsiani, 2006, p. 34). En el fondo es otra ironía sobre el mercado laboral: la necesidad de adaptación, formación continua y flexibilidad del 
entorno de trabajo contemporáneo, en una Europa sin fronteras para el comercio y la competencia, pero inerte en un sentido ético.

En Edén al Oeste, la metáfora de la uniformidad es más poética, pero también más cerrada. En el inicio se muestra un resort de vacaciones, donde el inmigrante protagonista se refugia clandestinamente, que se asemeja a una torre de babel. Esta urbanización, que parece una maqueta a escala del continente, cercada por alambradas y vigilada por la policía, sugiere una prisión a la inversa, "una Europa sin barreras y sin tratos distintivos, un único y gran país que corre el riesgo de tocar el corazón y de hacer soñar solo a aquellos que no lo habitan" (Leone, 2009, p. 21). Sin abandonar la idea anterior sobre la globalización, el director define aquí un espacio único, objeto de deseo del extranjero, e inexpugnable para él. Ya no solo se trata de integrarse, sino también de acceder.

Para Elías, el protagonista de Edén al Oeste, Europa es una única entidad, una especie de utopía. De modo paradójico, el convencimiento sobre esa comunidad homogénea es más intenso en él que en los propios ciudadanos europeos con los que se encuentra. La excepción viene dada aquí por el sentido simbólico que se le da a París, ciudad que sí aparece expresamente referida, e incluso homenajeada en el filme. Pero esta ciudad no es un espacio concreto, con connotaciones identitarias específicas. París es en el imaginario del personaje una especie de Tierra Prometida que concita una idea paneuropea de bienestar, una especie de mundo de Oz. El resto del viaje de Elías transcurre en los mismos términos genéricos que en Arcadia, sin que haya diferencias de ningún tipo en la caracterización espacial del continente, abundando en la representación de no lugares -según el concepto ya clásico, acuñado por Marc Augé (1992)- emblemáticos de la globalización (estaciones de servicio, autopistas, etc.).

La idea del capitalismo transfronterizo llega a su cénit en El capital. La acción narrativa del filme se traslada a todos los centros de poder financiero del mundo, de una forma física, a través de viajes relámpago entre Europa y Estados Unidos, o mediante la comunicación virtual. El discurso del cineasta en este caso incluye una reflexión paradójica entre la lógica positiva de la unidad idealizada, y las consecuencias de la uniformidad financiera real. 
Precisamente, el ejecutivo protagonista le dice a un familiar, veterano comunista desencantado que es crítico con su modo de proceder: "Deberías alegrarte porque hemos hecho realidad tu sueño de juventud" (Gavras, 2012), en referencia a una internacional sin fronteras, aunque se la de los capitales y la especulación.

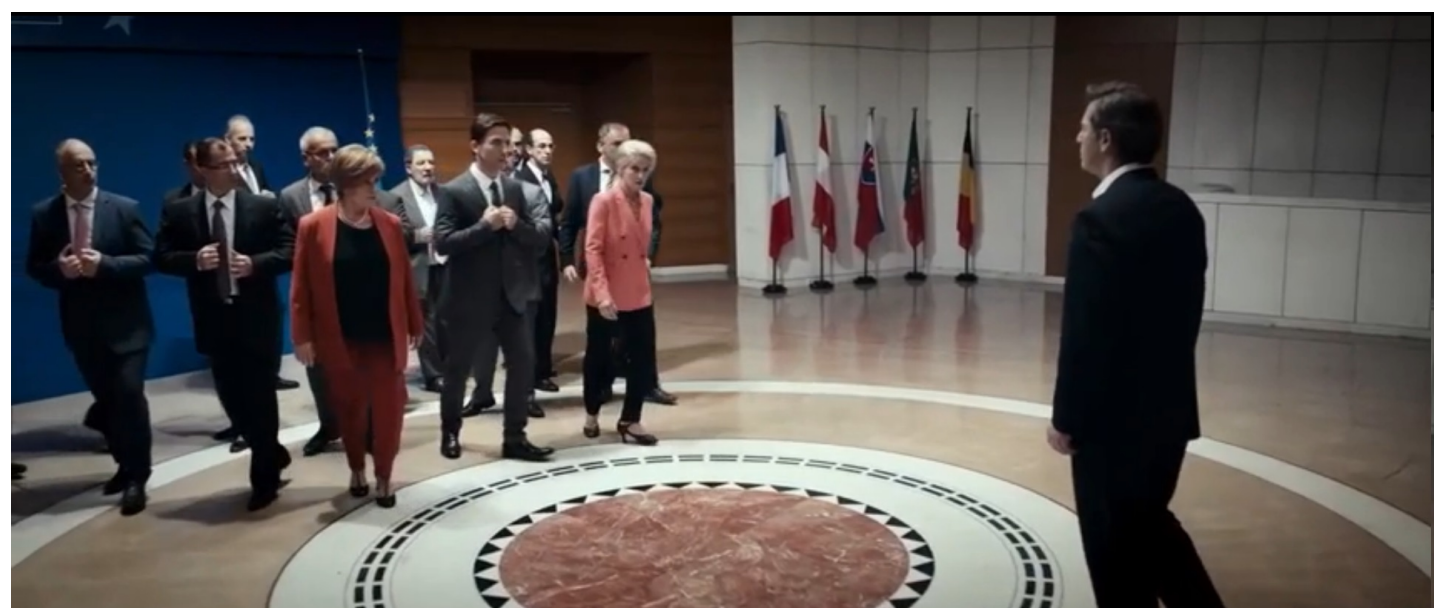

F1. Comportarse como adultos (Adults in the Room, Costa-Gavras, 2019). KG Productions (C).

En el caso de Comportarse como adultos la aproximación es más compleja. Existe evidentemente una -llorada - idea de una Europa única, pero por su argumento, centrado básicamente en las intrigas políticas de las instituciones de la UE, lo que se pone de manifiesto es precisamente la ruina de ese sueño de unidad. Lo que se plasma es la existencia de múltiples europas enfrentadas, que buscan una uniformidad de otro tipo, es decir una homogeneidad basada en una determinada ortodoxia económica. Gavras lo plasma a través de una secuencia tan insólita como reveladora. Al final del filme pone en escena una coreografía brechtiana, donde todos los líderes europeos bailan en torno al primer ministro Tsipras. Le rodean para que se una a la foto de familia de la cumbre, logrando precisamente una falsa unidad política. En cualquier caso, esa falsa unidad, queda simbolizada por la escenografía constante del filme: un laberinto no lugares, oficinas de cristal y despachos, que intensifican la idea de burocracia uniformizadora. En definitiva, esa querencia por los escenarios monocromáticos, idénticos, 
constante en los cuatro títulos, refleja la deshumanización del espacio europeo único en el que se desarrolla el relato.

\subsection{La Europa múltiple. El reflejo de sus habitantes}

Gavras construye un discurso complementario al del espacio homogéneo europeo, planteando la existencia de múltiples realidades, pero no basa esta existencia de múltiples europas en las idiosincrasias nacionales, sino en los comportamientos de sus habitantes, o en los posicionamientos políticos de las instituciones.

De este modo, tanto en Arcadia, como en Edén al Oeste, especialmente en esta última, la uniformidad espacial o económica que se muestra de Europa, está contrapuesta a la multiplicidad de actitudes individuales o colectivas de sus ciudadanos. Por ejemplo, en Edén al Oeste observamos un amplio abanico de reacciones ante la presencia de los inmigrantes, como a un grupo de turistas que se organiza para cazarlos, o unos racistas violentos que asaltan un campamento de refugiados. Estas actitudes negativas se mueven en dos líneas, la del rechazo expreso, que expone respuestas violentas, agresivas y de odio - en línea con el ideario de los partidos de extrema derecha europeos-, y la de la hipocresía que, bajo un aparente paternalismo, se aprovecha de la inmigración para sus propios intereses. No obstante, Gavras juega al despiste narrativo en cuanto a las expectativas. Los estereotipos con connotaciones sociológicas menos pulcras tienden a ayudar al personaje -como una pareja de rudos camioneros-, mientras que la clase media burguesa es más insolidaria, y sus miedos, los del imaginario europeo contemporáneo - la equiparación de inmigración y terrorismo- hacen su aparición, si bien también con excepciones puntuales, como la madura dama parisina (encarnada por Anny Duperey) que asiste al protagonista a su llegada a París.

Las múltiples europas que Gavras refleja en estos dos filmes tienen que ver con los estados de ánimo sobre la idea de Europa, sobre el aislamiento y sobre la integración. Esta colección de comportamientos diferentes, que adquiere la forma de un muestrario consciente, se convierte en una representación pormenorizada de tendencias contrapuestas, de orden 
político, en el seno de una Europa heterogénea, pero dividida por diferentes modos de encajar la globalización, por actitudes políticas o ideológicas individuales. Incluso el cineasta introduce ocasionalmente en estos dos títulos pequeños apartes que anotan circunstancias representativas, como unos basureros en huelga humillados por el dueño de un descapotable en Arcadia, que primero les miente para que le dejen pasar, y luego les ridiculiza insultándoles.

En cambio, en Comportarse como adultos sí que aparece una visión fragmentada que se sitúa al nivel de los estados-nación de la UE, y que ahonda en sus diferentes posicionamientos. No obstante, una de los elementos que se manifiesta claramente en el film, es que dichas posiciones no son abstracciones nacionales, sino que dependen de los representantes individuales -de los ministros, comisarios, etc.-, descritos en la película, que a fin de cuentas son personajes diseñados con los mismos mimbres que los anónimos de los otros títulos.

\subsection{El ciudadano europeo y el punto de vista narrativo}

Los personajes de ficción protagonistas de los diferentes relatos -individuos singulares- actúan como arquetipos sociales o políticos, de nuevo positivos o negativos según los casos. Gavras recurre a una fórmula tradicional en su cine desde sus primeros filmes, contraponiendo a un protagonista singular frente a un engranaje que lo aprisiona y que se convierte en la representación de la injusticia. Es decir, al margen de lo que represente ese personaje singular - a un colectivo, como al de los inmigrantes ilegales en Edén al Oeste o incluso a una posición político-ideológica como Varoufakis en Comportarse como adultos-, su acción individual es la que permite el avance de la narración y del discurso político de la película.

La existencia permanente de un punto de vista único, en cuanto a la focalización de la narración, y la estructura narrativa del viaje - un viaje del héroe simbólico, casi siempre físico (Jimeno, 2019) - permiten dotar a los protagonistas de tres niveles de interpretación. La primera es pragmática en tanto que actúa como personaje, con sus conflictos, permitiendo el desarrollo del relato. Las otras dos son poéticas. Una es de carácter diegético, pues se 
sitúa dentro de la narración, representando a un determinado colectivo. La otra es externa y tiene que ver con el nivel de la enunciación narrativa, en la medida en que el personaje y el espectador quedan conectados, e incluso identificados.

Sucede, por su condición de antihéroe, de víctima asesina, con el protagonista de Arcadia, con el que el espectador llega a empatizar, deseando que logre sus objetivos criminales, y esperando al mismo tiempo como el personaje- que la situación se resuelva para que no tenga que seguir matando. En este caso, la construcción del punto de vista y de la identificación es la más compleja de los tres filmes. Gavras logra que el espectador empatice con él por varias vías. La propia construcción de fábula del relato sitúa los crímenes en el espacio de una extensión imaginaria de sus deseos, pero sus problemas - la pérdida del empleo, o su crisis matrimonialestán trazados con naturalismo.

Esta construcción compleja se deja sentir claramente en el tercer crimen, porque el espectador tiene ocasión de conocer a la víctima. Se trata de otro perjudicado de la crisis, con un carácter débil, casi patético, que trabaja en ese momento como camarero. No obstante, tras una conversación, en que este personaje expone sus ideas - proponiendo eliminar a los pensionistas, por ejemplo- el dilema ético se aclara. El espectador y el protagonista transforman su visión al mismo tiempo y pierden respeto por este personaje, que se va a convertir -irónicamente- en un modelo de su propia propuesta política de exterminio.

Gavras incide en el subrayado formal de esta construcción de la perspectiva, y del cambio que experimentan Bruno y el espectador al mismo tiempo: muestra a Bruno de espaldas, reflejado en un espejo, mientras conversa con su competidor, en el momento en que sus simpatías iniciales se convierten en irritación. Gavras explica este punto de forma diáfana:

Es un proceso progresivo que culmina cuando la gente sale del cine y se pregunta: ¿tan negativo soy yo, que me puedo identificar con un individuo así? La reacción simultánea de aceptación y de rechazo era esencial. Sin identificación no habría nada, ni personaje ni película. Sin ironía, el filme 
tampoco sería el mismo o, por lo menos, no establecería la misma relación con el espectador. (Riambau, 2007, p. 202).

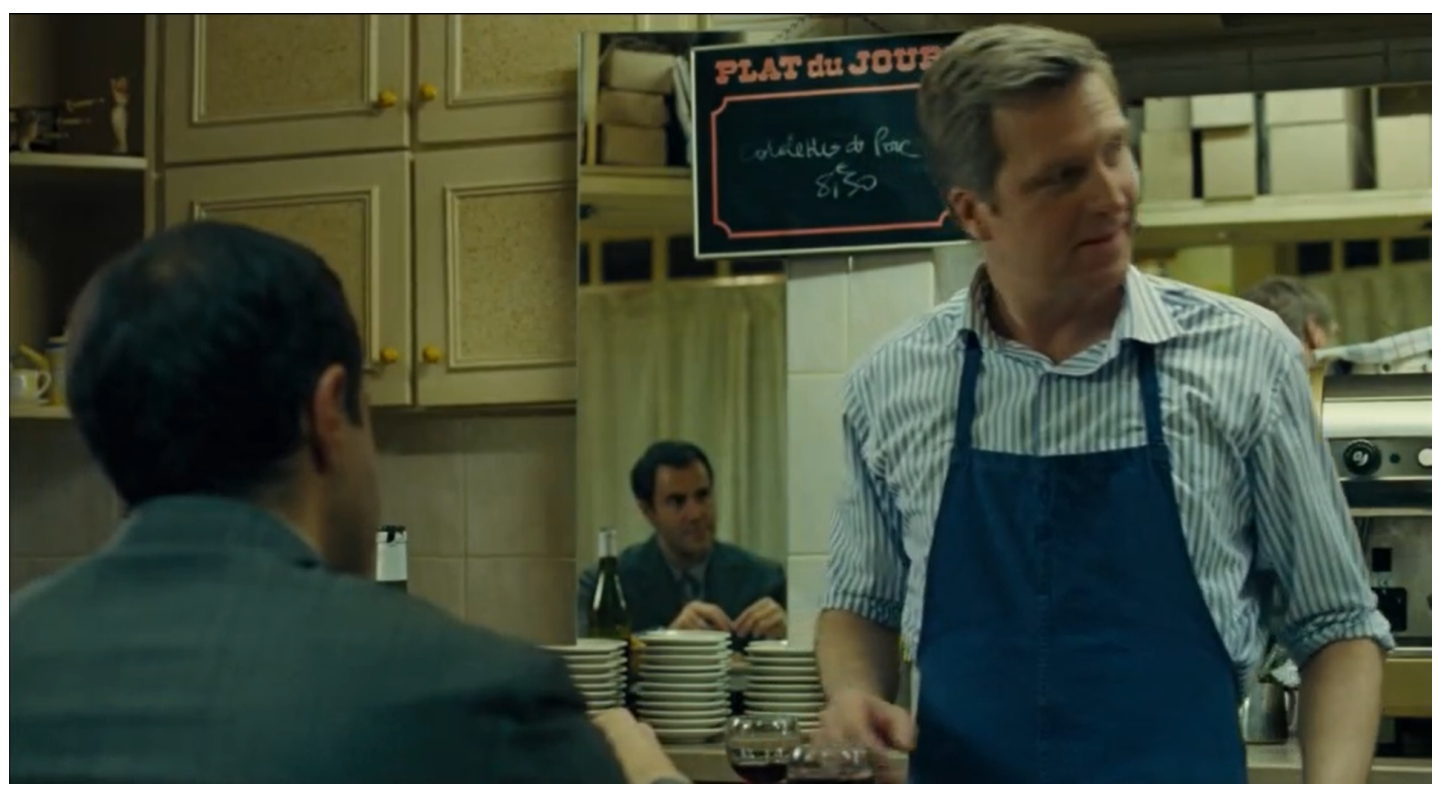

F2. Fotograma de Arcadia (Le couperet, Costa-Gavras, 2005). KG Productions (C).

Por ejemplo, en Edén al Oeste, se sigue un patrón narrativo similar: la expectativa, juicio parcial o definitivo sobre los personajes episódicos del relato viene filtrada por el punto de vista. Cuando Elías, tentado como un adolescente inocente por el sexo y el alcohol, mantiene una aventura con la turista, tanto él como nosotros, espectadores, vamos sufriendo una transformación en nuestra percepción de este personaje: pasamos de una atracción inicial, al rechazo por su condición de explotadora, a volver al final a sentir simpatía por el personaje - cuando Elías está a punto de robar su cartera y descubre un sobre con dinero-. El cineasta va controlando con precisión las expectativas del público. En este caso la empatía es doble, porque el peso narrativo del punto de vista se combina con la previsible actitud compasiva -incluso de superioridad- de un espectador europeo de clase media que se compadece del personaje-víctima.

La única excepción a esta identificación empática entre personaje y espectador es el tiburón financiero de El capital. Es uno de los escasos protagonistas de Gavras que, ostentando el punto de vista del relato, ofrece una posición a priori antipática para el público, aunque el personaje -encarnado por 
un actor cómico muy popular en Francia, Gad Elmaleh- pueda generar una cierta atracción, una especie de fascinación por el mal. Es un planteamiento contradictorio y complejo. De nuevo el personaje atrae, de forma intuitiva, mientras repele, de modo racional, al mismo tiempo. No obstante, ante la imposibilidad de generar una identificación emocional completa, Gavras utiliza otro recurso y por primera vez en sus largometrajes rompe la cuarta pared. El protagonista de El capital le habla directamente al público, explicando sus acciones o interpelándole, lo que además redondea su cinismo -un recurso empleado posteriormente por otros dos personajes en ascenso en House of Cards (Beau Willimon, 2013-2017) y en El lobo de Wall Street (The Wolf of Wall Street, Martin Scorsese, 2013), título con bastantes similitudes con El capital. Esta actitud constituye una provocación constante al público, elevada en el abrupto final, en el que prácticamente anuncia al espectador el apocalipsis final, antes de un corte a negro.

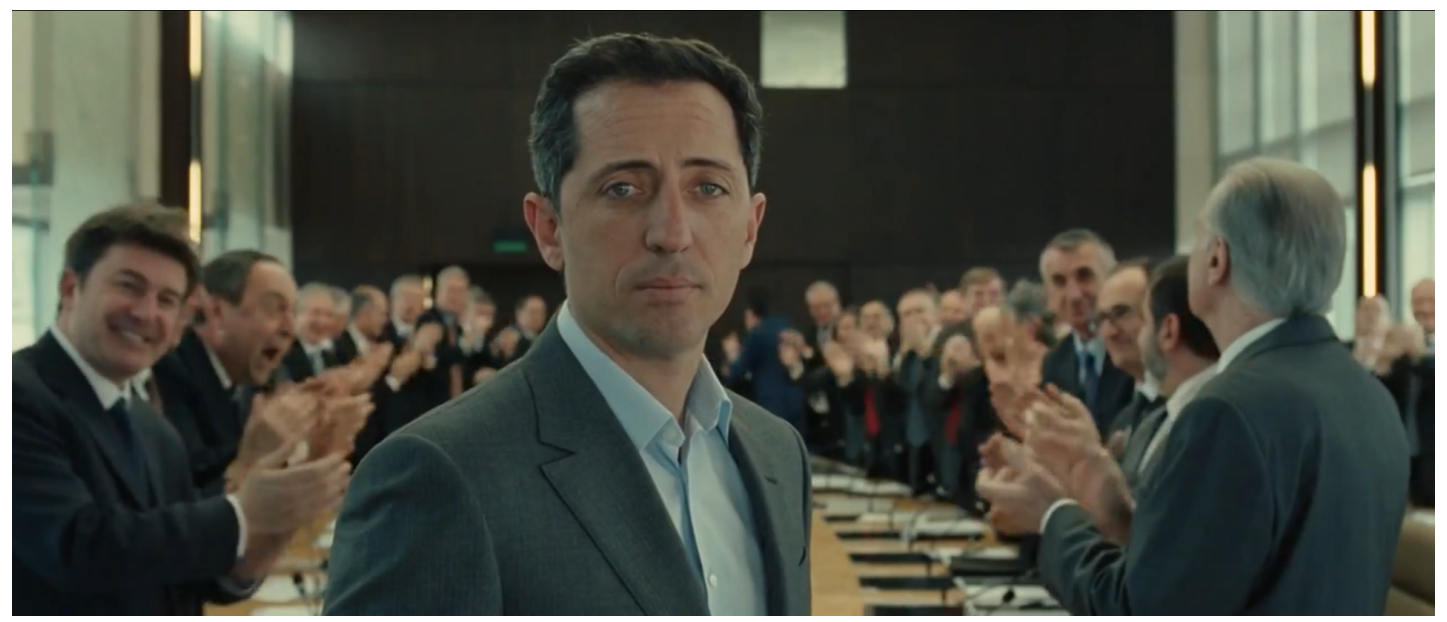

F3. Fotograma de El capital (Le capital, Costa-Gavras, 2012). KG Productions (C).

La identificación entre personaje y espectador se efectúa también con el personaje de Varoufakis en Comportarse como adultos, erigido en un símbolo de la resistencia política mientras se desplaza continuamente de una capital europea a otra, y concitando la empatía del espectador, precisamente por los atributos diferenciados que se le dan con respecto al arquetipo de burócrata profesional. Varoufakis es moderno, brillante, combativo pero educado, en contraposición a la hipocresía y arrogancia de sus colegas 
europeos. El personaje concita la simpatía del público -más allá de lo que pueda considerarse del referente real-, porque está construido con mimbres de héroe trágico, mostrando sus fortalezas, pero también sus puntos débiles.

\subsection{Sueño y realidad de Europa}

Precisamente, al poner en relación la concepción de Europa con el punto de vista de quien la observa -o la sufre en base a los relatos que se presentanestos filmes articulan una doble visión del continente, que tiene que ver con su concepción ideal $-\mathrm{y}$ deseable- o con su planteamiento realista, normalmente en sus elementos negativos, lo que se relaciona también con la dualidad de la Europa abierta y la Europa cerrada. Gavras vuelve a servirse de la elaboración visual del punto de vista para abordar esta relación. La puesta en escena del director plasma siempre -y no solo en estos cuatro filmes- al protagonista, a bordo de un vehículo, mirando al exterior, mientras se muestran los reflejos de lo que observa en la ventanilla. Esta elección visual y de montaje pone en relación al individuo con la realidad -que le rodea o que le aprisiona-, incluyendo ocasionalmente -como función poética consciente- la idea del reflejo. Se integra aquello que se está viendo, pero también lo que se está imaginando. Es el caso, entre otros, de la llegada de la comitiva griega, llena de esperanzas, a su primera reunión en Bruselas, en Comportarse como adultos.

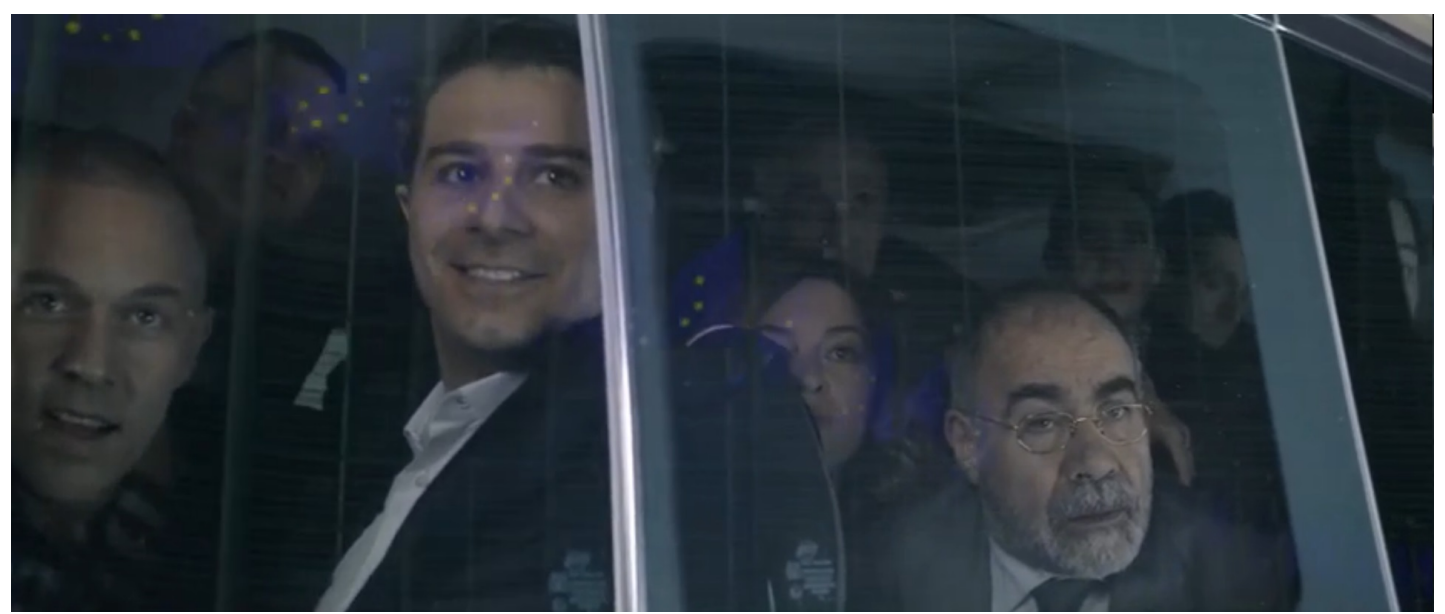

F4. Comportarse como adultos (Adults in the Room, Costa-Gavras, 2019). KG Productions (C). 
Curiosamente, aunque la representación de la subjetividad inconsciente ha estado siempre presente en la obra de Gavras, en estos filmes se potencia la utilización de recursos de orden cuasi fantástico para expresar los anhelos imaginarios de los personajes. En Arcadia y en El capital, a través de determinadas rupturas diegéticas observamos las reacciones que desearía tener el personaje con sus semejantes, a menudo violentas, e incluso vemos, en el caso de Arcadia, su futuro inmediato anticipado en un flash-forward. El espacio del sueño sobre el futuro queda así expuesto de forma individual, pero el cineasta apela a esas aspiraciones con otros recursos, cercanos también a un realismo mágico. En Arcadia es constante la aparición de anuncios publicitarios casi surrealistas, presentes en grandes camiones, vallas de la autopista, y toda suerte de soportes, con cuerpos femeninos desnudos, nuevas tecnologías y automóviles. Estas interrupciones de fondo, que funcionan como apartes complementarios, son un recordatorio constante de la existencia de una sociedad mercantilizada, donde la publicidad es la metáfora de una búsqueda obsesiva de la felicidad basada en el consumo. Gavras explica este sentido: "Es algo que afecta directamente al personaje y, a la vez, se refiere a lo que hoy en día sucede con la publicidad como algo que ha degenerado por completo y desempeña un papel muy negativo en el seno de la sociedad" (Riambau, 2007, p. 201). El sueño europeo es aquí una suma de sueños individuales. Se reduce a la aspiración de acumular materialmente.

Por el contrario, en Edén al Oeste el sueño de Europa sí que corresponde a una idealización positiva de la utopía comunitaria, en base a la mirada de un forastero inocente, que aún confía en la posibilidad de encontrar una especie de paraíso en la Tierra. Aquí el sueño emocional del personaje, en la consideración de Europa como un espacio abierto e integrador lleno de oportunidades, más allá de los materiales, coincide con el del cineasta, en su propia experiencia personal como emigrante.

Dejar Grecia en esa época, para mí, para alguien de mi clase, no era morir un poco, como dijo el poeta, sino renacer. Era huir de la miseria, no solamente de la económica, sino de la otra, esa en la que toda esperanza o proyecto es 
impensable (...). Era ir hacia la luz, a cumplir un sueño, incluso si ese sueño era impreciso. (Gavras, 2018, p. 11).

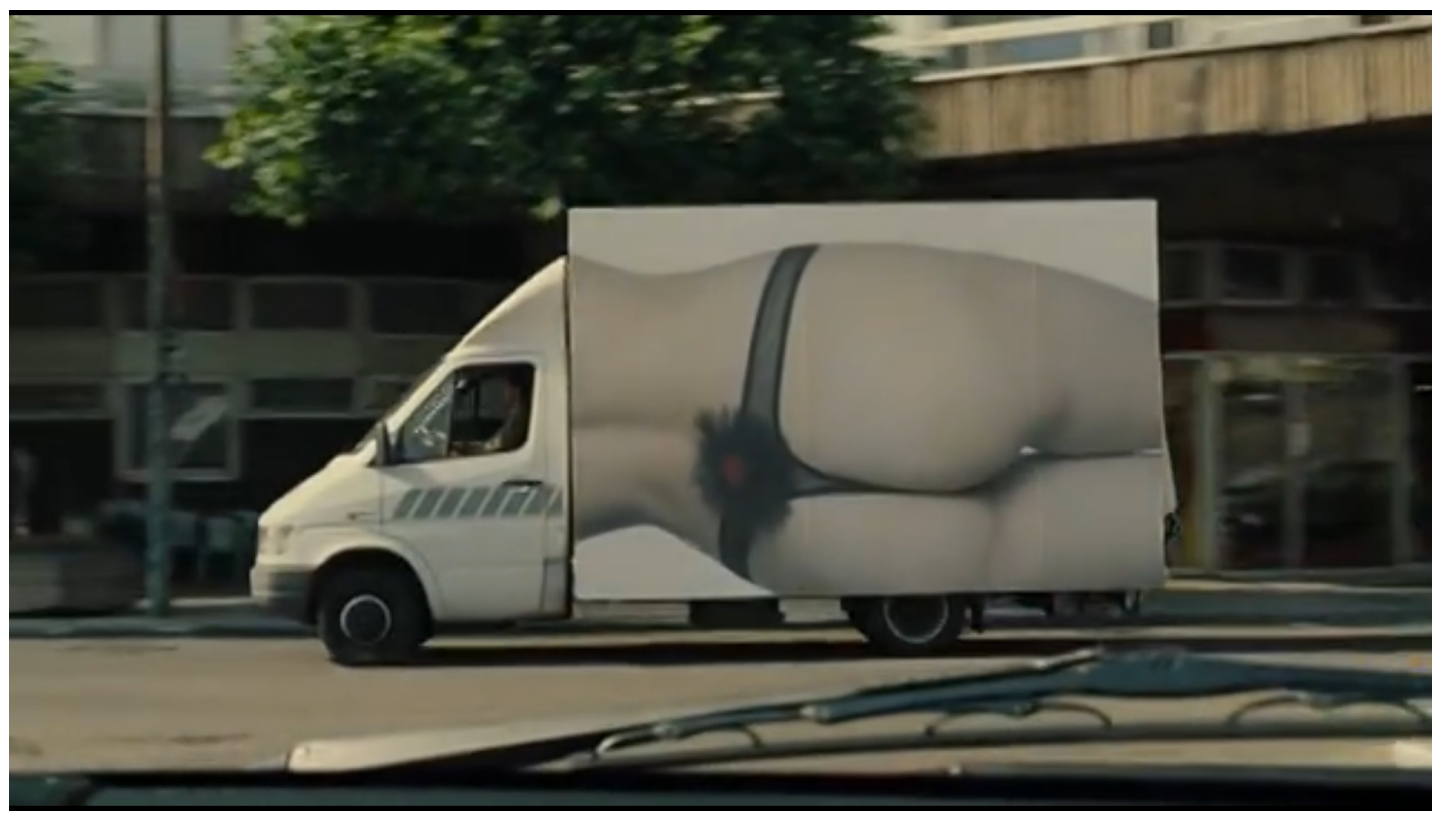

F5. Fotograma de Arcadia (Le couperet, Costa-Gavras, 2005). KG Productions (C).

Gavras dota de notable fuerza a esta idea onírica, lo que justifica el enfoque de fábula de iniciación que tiene la obra. El personaje de Elías es la plasmación de la inocencia, no exenta de cierta picaresca. Su mirada concreta tiene algo de infantil, y su visión del mundo es la de un niño, sometido eso sí a toda clase de pruebas. Edén al Oeste marca de modo expreso la división entre la Europa soñada y la de la realidad, hasta el punto de que esta dicotomía es la esencia de la película desde su propio título. Como explica Fernández Valenti: "es un cuento moral sobre las peripecias de un inmigrante en una Europa de las maravillas, que no es tan maravillosa como se pretende”. (2009, p. 28).

Este sueño europeo - el individual y el colectivo- queda en entredicho por la realidad abrupta que lo interrumpe, a partir de las interferencias de un sistema económico y político que avanza en otra dirección, como muestra $E l$ capital, anulando toda aquella aspiración que no sea la del éxito económico, y la acumulación de dinero. En este sentido, el conflicto del protagonista, en condición de Fausto moderno, pasa por renunciar a todos sus otros sueños posibles - sentimentales, intelectuales- para obtener el triunfo como banquero. 
En Comportarse como adultos, el choque entre la Europa real -descrita como un laberinto burocrático y mezquino- y la Europa soñada, basada en el espíritu de colaboración y solidaridad entre los países, adquiere un peso aún más conceptual, que pone en la diana el debate en torno a la construcción de la Unión Europea. En su plasmación, Gavras también se sirve del realismo mágico, y particularmente de una querencia musical muy atípica, basada en las raíces cultas y populares griegas - con la tragedia y el sirtaki, el baile popular, como leit motiv - que pone en escena coreografías y representaciones distanciadas que apuntalan el discurso del film, la tensión entre la defensa del sueño fundacional y la renuncia pragmática a dicha aspiración.

\subsection{La Europa de los parias y la Europa de las élites}

En coherencia con la plasmación del conflicto entre dos visiones de Europa, se pone de manifiesto también otra dualidad evidente, de orden palpable más que conceptual, que tiene que ver con la realidad del poder: la existencia de una Europa de los parias y de una Europa de las élites, que podría sintetizarse en una confrontación entre víctimas y verdugos.

En Arcadia y Edén al Oeste, los protagonistas que ejercen el punto de vista corresponden a la categoría de los parias. Elías, el inmigrante, lo es sin subterfugios, desde el primer momento: no tiene nada e intenta sobrevivir como puede. Gavras lo representa cubierto de excrementos cuando se oculta en el resort de vacaciones; viajando en una camioneta que transporta cerdos; o trabajando en una planta de reciclaje. Esta asociación no es especialmente sutil, pero tienen el doble valor de tener una función poética obvia, y una función pragmática indiscutible, pues el personaje desempeña en la diégesis tareas reservadas habitualmente a la inmigración ilegal y a las clases sociales menos favorecidas, que acaban teniendo una simbología social directa en la propia realidad, además de incidir en el conflicto ya analizado entre esta realidad y la aspiración del personaje.

En Arcadia, lejos de establecer una posición maniquea, Gavras otorga a su personaje la doble condición de víctima y verdugo. Bruno es un paria sobrevenido - de un día para otro, pasa de ser un trabajador de clase 
burguesa a un parado- pero basa su supervivencia en la eliminación de los demás, animado por un sistema que no le deja muchas más salidas. El discurso es más complejo aquí, porque lo que indica es que para salir de esa situación el paria debe competir con otros parias hasta las últimas consecuencias. La élite queda intacta.

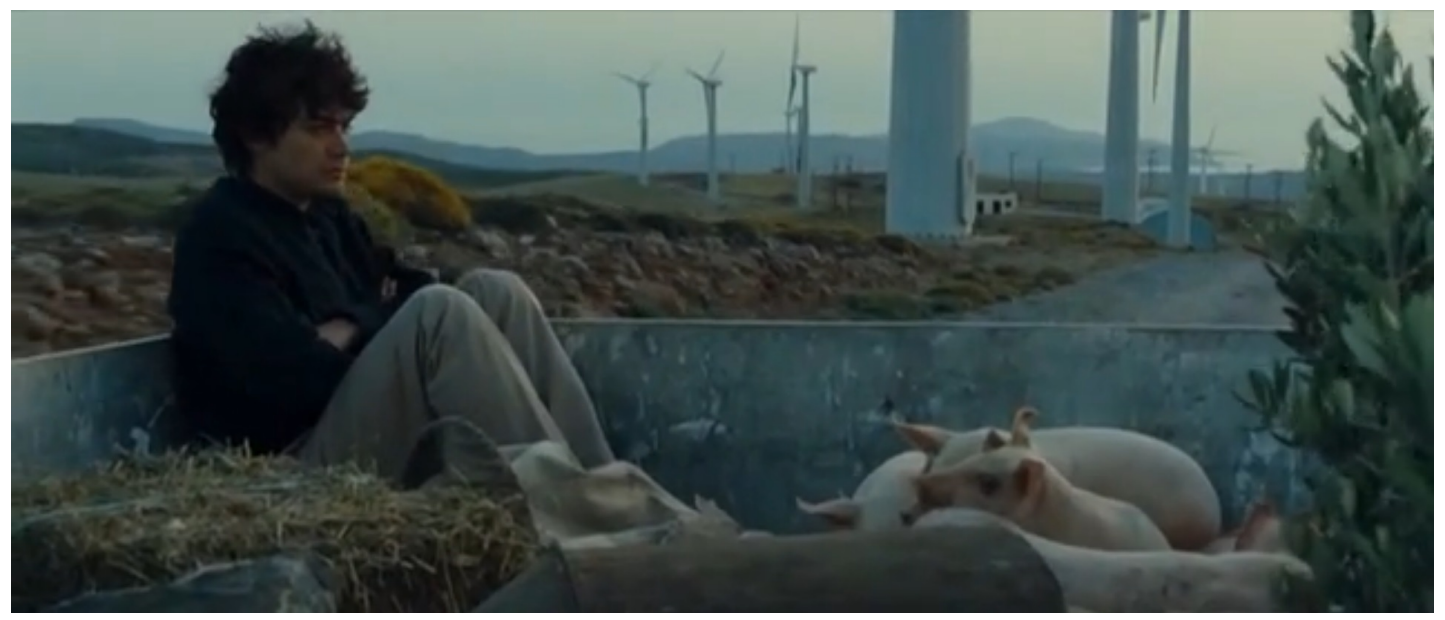

F6. Fotograma de Edén al Oeste (Éden à l’Ouest, Costa-Gavras, 2009). KG Productions (C).

En El capital y en Comportarse como adultos, en lo referido al punto de vista, Gavras cambia de guía narrativo, y se centra en dos personajes integrados en la Europa de las élites. El personaje del banquero de El capital lo es de un modo monolítico, sin que su conciencia -representada por una economista que le sirve de asesora- incida lo más mínimo en el logro de sus fines individuales. La Europa de los parias está oculta en esta película, es una elipsis significante desde el punto de vista narrativo. Apenas aparece de modo fugaz, virtualmente, cuando los empleados que van a ser despedidos son vistos a través de una pantalla, o cuando Tourneuil se cruza con dos personas sin hogar en la calle. Esta ocultación no es casual. Representa el olvido del personaje, y de su Europa de las élites. Los parias no existen.

Comportarse como adultos también refleja la Europa de las élites, la de los tableros de poder, pero tiene una aproximación más matizada. El protagonista, el único con un referente real expreso, Varoufakis, exitoso economista glamuroso y ministro, pertenece sin duda a esa élite, pero Gavras le dibuja como un representante por poderes de esa otra Europa, también 
elíptica. Incluso ante sus dudas, en la batalla institucional europea, esa Europa social aparece excepcionalmente, representada de nuevo con ecos de Brecht, a partir de la presencia de un grupo de manifestantes mudos, vestidos de negro, y hieráticos, que avanzan lentamente, interpelando silenciosamente al protagonista en un restaurante. En el film aparece además otra división conceptual entre parias y élites, esta de carácter colectivo, sintetizada también en los diversos líderes y personajes políticos de la acción: la de los países ricos, liderados por Alemania, cuyo ministro Schäuble (Ulrich Tukur) es caracterizado como un personaje siniestro, casi un villano de thriller, y la de los países pobres y endeudados - los PIGS según la censurable terminología acuñada en el norte para referirse a Portugal, Italia, Grecia y España-, sintetizados en la figura del personaje protagonista. En el conflicto de poder, no hay grandes diferencias entre el estigma de los parias individuales y el de los colectivos a la hora de calibrar sus opciones de éxito. En el fondo, y al margen de su condición de partida, todos los relatos dan cuenta de un intento de los personajes por integrarse o por ascender en el sistema. En Arcadia, se trata de regresar al mercado laboral, y en Edén al Oeste de la adaptación a la vida europea de un inmigrante. En El capital Tourneuil busca acceder a la cúspide del sistema financiero, e incluso Varoufakis, en Comportarse como adultos, trata de ser aceptado como un igual - cosa que no logra- en los mandos de decisión de la Unión Europea. La diferencia es que solo los personajes que se adaptan a las reglas trucadas del sistema logran dicha integración, precisamente por que cumplen con su lógica de forma extrema (las reglas del mercado, la competencia, la especulación) y triunfan, aunque su victoria sea pírrica e inmoral. Es el caso también del personaje, más secundario, del primer ministro Tsipras en Comportarse como adultos, incorporado al final a la foto de grupo porque se rinde a las demandas de sus socios europeos, aún a cosa de traicionar sus principios políticos. Por el contrario, los que no se adaptan porque no ceden, como Varoufakis, o porque no tienen la capacidad de hacerlo, en su condición de parias absolutos, como Elías, quedan fueran del engranaje. 


\section{Conclusiones. El desenlace de la idea de Europa}

Siguiendo el desenlace de las cuatro películas, en conexión con las reflexiones planteadas en el desarrollo del texto, podemos hallar la clave del planteamiento narrativo y político de Gavras en torno a la realidad que plasma. Al observar los desenlaces de sus filmes, aparece siempre la sombra de la derrota, y la imposición de una cierta ambigüedad o ironía, pero la dualidad no desaparece. Gavras logra un complejo equilibrio entre la exposición manifiesta de una realidad dura e injusta, negativa, manteniendo al mismo tiempo una lectura distanciada, que permite el espacio para la resistencia. En cada uno de los cuatro títulos lo hace de un modo diferente al nivel de detalle, pero muy similar en cuanto al concepto.

En Arcadia, el personaje logra su objetivo: un nuevo empleo, pero se convierte a su vez en un cazador convertido en pieza para otros cazadores. Es un final positivo para el personaje a corto plazo -que además se libra fortuitamente de la acción de la justicia-, pero negativo y visceral en un sentido político, puesto que "consigue el éxito al precio, no solo de no oponerse al sistema -como otros héroes de Gavras-, sino de aplicar sus máximas hasta las últimas consecuencias". (Jimeno, 2014, p. 1112). Es decir, el funcionamiento de la competencia en el mercado no tiene desenlace, es continua y cíclica. Este desenlace es similar a la de El capital, en la que el protagonista también logra su propósito individual -aunque pierda en el terreno sentimental-, ahondando en la lógica perversa del marco político descrito.

Los héroes de los otros dos filmes, Edén al Oeste y Comportase como adultos, terminan en fracasos más evidentes, particularmente Varoufakis en Comportarse como adultos, que pierde sus opciones y dimite, mientras el primer ministro Tsipras acepta las condiciones del rescate. En cambio, en Edén al Oeste, Gavras opta por una determinada ambigüedad poética que suspende el fracaso parcialmente, e insiste en el espacio para la esperanza. $\mathrm{Si}$ bien el protagonista logra llegar a París, su aventura parece verse truncada por la carga de un grupo de antidisturbios. Este final hibernado, es sustituido por la apuesta magicorrealista más intensa de la obra de Gavras. El 
personaje, con la varita mágica que le ha proporcionado un mago - personaje clave en el film, que aparece en varias ocasiones- hace "desaparecer" a los policías. Lo extraño e incluso insólito de este final, a pesar de la condición fabulesca del relato, constituyen una apuesta decidida del director, incluso muy arriesgada en términos de congruencia narrativa, por el ideal del sueño europeo. Como si puntualmente se cerrasen los ojos a lo real y lo previsible. Gavras articula un discurso basado en dos presupuestos, que funcionan como extremos ya apuntados en la deriva narrativa de sus filmes: la exposición de los hechos reales, describiendo una Europa plegada a los intereses económicos y del mercado; y el espacio para las alternativas, situadas en un espacio imaginario. En la vuelta de tuerca que proponen los diferentes desenlaces, cada uno con sus matices, aparece la apuesta del director por un discurso de activismo y de esperanza, sustentado en un posicionamiento lúcido y crítico. Es decir, no existe ingenuidad en la posibilidad del discurso esperanzado, pero tampoco desánimo o cinismo en la enumeración de las injusticias. El resultado es una llamada a la resistencia, desde su posición de narrador, manteniendo intacta la consideración de la obra cinematográfica como herramienta de acción política sobre la realidad.

\section{Referencias bibliográficas}

Augé, M. (1992). Non-lieux. Introduction à une anthropologie de la surmodernité. Paris: Seuil.

Aumont, J. \& Marie, M. (2002), Análisis del filme. Barcelona: Paidós.

Bordwell, D. (1996). La narración en el cine de ficción. Barcelona: Paidós.

Bordwell, D. y Thompson, K. (1995). El arte cinematográfico. Barcelona: Paidós.

Combs, J. (1993). Movies and Politics. The Dynamic Relationship. Nueva York: Garland Publishing.

Gavras, C. (2018). Va où il est impossible d'aller. París: Seuil.

Gavras, C. (2005). Le couperet. Francia-Bélgica-España: K.G. Productions et al.

Gavras, C. (2012). Le capital. Francia: K.G. Productions.

Jimeno Aranda, R. (2014). La aproximación a la realidad desde la perspectiva del cine político europeo contemporáneo. Dos Miradas: Marco 
Bellocchio y Costa-Gavras. Tesis Doctoral. Universidad Complutense de Madrid.

Jimeno Aranda, R. (2019). Adults in the Room (Comportarse como adultos). Miradas de cine, 17 de octubre de 2019. https://miradasdecine.es/2019/10/adults-in-the-room-comportarsecomo-adultos-de-costa-gavras.html

Leone, L. (2009). Verso l'Eden. Cinefórum, vol. XLIX, 483, pp. 41-42

Martínez, L. (2020). Costa-Gavras: "¿Qué les habría pasado a los pacientes del Covid-19 si hubiesen tenido que pagar su atención hospitalaria en un sistema privado?”. El Mundo, 25 de abril. https://www.elmundo.es/cultura/cine/2020/04/25/5ea32fdo21efaoc d418b4658.html

Morsiani, A. (2006). Serial killer per lavoro. Cacciatore di teste. Cineforum 452, pp. 32-34

Navarro, A.J. (2012). El baile de los vampiros. Dirigido por, 427, pp. 30-31.

Ravanello, O. (2009). Costa-Gavras: Seeks his Eden through filmes. Neokosmos, 18 de agosto de 2009. https://neoskosmos.com/en/1637/costa-gavras-eden-is-west/

Riambau, E. (2007). De traidores y héroes. El cine de Costa-Gavras. Guadalajara (México): Festival Internacional de Cine de Guadalajara y Universidad de Guadalajara.

Talin, M. (2014). Economic Crisis and Employment Change: The Great Recession. En Gallie, D. (Ed.). Economic Crisis, Quality of Work and Social Integration: The European Experience, Oxford: University Press Oxford, pp. 1-26.

Vallés, J.M. (2003). Ciencia Política. Una introducción. Barcelona: Ariel. 